\title{
Complex disposition of an enigmatic pathogen: rare electron microscopic manifestations in nasal rhinosporidiosis
}

\author{
Dhara B. Dhaulakhandi', Alok K. Ravi ${ }^{1}$, Lalit C. Garg ${ }^{2}$, Karvita B. Ahluwalia ${ }^{1}$ \\ ${ }^{1}$ Cell Biology and Electron Microscope Section, Department of Biophysics All India Institute of \\ Medical Sciences, New Delhi, India \\ ${ }^{1 \psi}$ Department of Ocular Biochemistry, Dr. R.P. Centre for Ophthalmic Sciences, AIIMS, New Delhi, \\ India
}

${ }^{2}$ Gene Regulation Laboratory, National Institute of Immunology, New Delhi, India

\begin{abstract}
Rhinosporidiosis is a polypoidal disease of the nose and mucocutaneous tissues, the diagnosis of which is based on the presence of round bodies believed to be causative agents of the disease. Historically, the round body has been considered to be a sporangium of a fungus Rhinosporidium seeberi but without any convincing evidence. Round bodies contain numerous daughter cells, which are likely in the infective stage and are shed through a rupture in the wall of the round body. The released single-celled organisms eventually develop into round bodies on availability of suitable transformative trigger and favourable environment. Surgical excision of the polyp by electrocautery is the only effective treatment; however, recurrence may occur due to spillage of infective endospores in the surrounding mucosa during removal. There are many enigmatic features of the causative agent of this disease, which have been baffling researchers for more than a century. Here we present some rare electron microscopic and previously unreported features of the coat of the round body and single-celled organism in nasal rhinosporidiosis.
\end{abstract}

KEYWORDS: polypoidal, round body, rhinosporidiosis, s-layers, SEM, TEM

\section{INTRODUCTION}

Rhinosporidiosis is one of the several polypoidal diseases of the nose. Nasal polyps are soft, benign, abnormal growths, which develop from the mucous lining of the nose. Anterior nares, inferior turbinate, septum, or the floor may be involved, leading to difficulty in breathing and nasal obstruction. A round body (RB) is a distinctive feature of rhinosporidiosis. The identification of the round body and enclosed daughter cells has been challenging medical and basic scientists for the past hundred years ${ }^{1,2}$. Mucous membranes of the nose and nasopharynx are predominantly affected, but occasionally the lips, the palate, the uvula, the maxillary antrum, conjunctiva, the lacrimal sac, the epiglottis, the larynx, trachea, bronchus, the ear, the scalp, the skin, the penis, vulva and vagina may also get infected. Osteolytic lesions in the bones of the hands and feet have also been reported ${ }^{3}$. How- ever, rhinosporidiosis is usually limited to surface epithelium but may occasionally be widespread with visceral involvement. Polyp formation causes nasal obstruction and bleeding. Asymptomatic nodular skin lesions with multiple, discrete, sessile and lobulated or pedunculated, smooth and warty lobes of variable sizes and shapes are found. The polyps are usually pink to purple and friable. The pink colour is due to dense vascularity in the lesion. The polyps are chronic, but not painful.

The symptoms of the disease involve epistaxis, viscid nasal discharge, irritation, difficulty in swallowing and partial nasal obstruction. Occurrence of the polyps may be detected much later than their birth, as the patient might have not sought advice for several years until benign polyps started expanding and causing obstruction. Primarily located in the vestibule and usually attached to the septum, they may spread backwards into the nasopharynx and, sometimes, even 
hang down into the oropharynx. Affected individuals exhibit a swollen and hyperaemic nasal mucosa covered with copious viscid secretion containing spores. Nasal discharge may also show presence of spores on microscopic examination. The mode of transmission of the disease is not known. Although most believe an aquatic route of infection, it is not known why only a certain proportion of individuals exposed to waters catch the disease. The life cycle of the causative agent has not been well understood and susceptibility to disease has not been convincingly established immunologically or otherwise.

There are very few studies focusing on the detailed ultrastructure of the wall of the sporangium and this aspect has been very superficially touched. KannanKutty and Teh (1974) used electron microscopy (EM) to study formation of the cell wall in the sporoblast of Rhinosporidium seeberi ${ }^{4}$. These authors described the electron microscopic observations in different phases of the life cycle of the organism. They found condensation of a microfibrillar mantle that surrounded the immature form; the plasma membrane fused with the inner layer of this mantle to form the limiting membrane, and traced the mode of the development of the cell wall of the immature sporoblast from the condensation of the microfibrillar mantle. Besides, organized concentric lamellated bodies in early nodular bodies were found. This study convincingly demonstrated that a mature round body consisted of numerous single-celled organisms containing many lipid bodies and other organelles. Moses et al. (1991), with the help of scanning EM studies, revealed that the sporangium was filled with numerous spherical spores ${ }^{5}$. Authors demonstrated that the sporangium contained three distinct layers, the peripheral and inner layers being electron-lucent, whereas the middle layer being electron-dense. The inner layer had an irregular surface. Azadeh et al. (1994) showed through EM studies that the early nodular bodies had a fibrillar wall with spherical to elliptical, organized, ring-tree-like lamellated structures in the matrix ${ }^{6}$. Authors observed numerous fibrils apparently incorporated into the outer surface of the wall. These observations were later confirmed by Venkateswaran et al. (1997), who demonstrated that sporangium had a thick wall and contained many mature endospores ${ }^{7}$.

Here we present a detailed account of some intriguing ultrastructural features of the inner and outer coat of the round body.

\section{MATERIAL AND METHODS}

Three samples of excised polypoidal tissues of rhinosporidiosis were collected in sterile PBS (phosphatebuffered saline) ( $\mathrm{pH}$ 8.0) from the ENT Department of AIIMS (All India Institute of Medical Sciences). One sample came from the ENT Department of Safdarjung Hospital, Delhi. Surgically removed polypoidal masses $\left(1 \mathrm{~cm}^{2}\right)$ were collected in a $50 \mathrm{ml}$ falcon tube containing $15-20 \mathrm{ml}$ sterile PBS solution. The tissue mass was gently washed in sterile glass distilled water by rotating the tube up and down with gentle shaking in between for 15-20 minutes (this step helps getting the RBCs (red blood cells) away from the rhinosporidium tissue). Supernatant containing debris, epithelial cells and some shed-off round bodies were collected in a separate tube. The tissue was now placed in a $50 \mathrm{ml}$ falcon tube containing $15-20 \mathrm{ml}$ sterile PBS solution ( $\mathrm{pH} \mathrm{8.0)}$ and washed with moderate shaking 5-10 times for 20 minutes. Supernatant of each step was collected in a separate tube. To get rid of the microbial contaminants, the tissue was placed overnight in a Cycloserine antibiotic solution of $50 \mu \mathrm{g} / \mathrm{ml}$ concentration for $6 \mathrm{hrs}$. After antibiotic treatment, the tissue was again washed 3-4 times gently in sterile glass distilled water. The supernatant was collected each time in a separate tube.

The tissue was then placed on a sterile petri dish inside laminar hood (UV lights were put on 15-20 minutes before the actual time of dissection) and teased into 20-30 small $1 \mathrm{~mm}^{2}$ pieces using a fine sterile blade or scalpel. The presence of contaminating microbes was checked by placing a plane Amp-Agar plate in the room where the inoculation work was done, inside the laminar hood, and which had been previously fumigated with formaldehyde. Dotted grain or bead-like round bodies appeared on the polyp lobules. These excised lobules were placed in a fresh sterile $50 \mathrm{ml}$ falcon tube containing $10 \mathrm{ml}$ sterile PBS ( $\mathrm{pH} 7.0$ ), $1 \mathrm{ml}$ sterile CBEML (Cell Biology \& Electron Microscopy Laboratory) medium and $5 \mathrm{ml} 25 \%$ sterile glycerol. This solution helped in reducing the force of adhesion between the tissue and the round bodies and, to some extent, helped in maturation of immature round bodies into mature ones, thereby facilitating the release of the round bodies from the polyp lobules. The dissected polyp lobules $\left(\sim 1 \mathrm{~mm}^{2}\right)$ were vigorously shaken in a capped sterile greiner tube 8-10 times for 10-15 minutes each time. Small grain-like round bodies were released from the lobules. These round bodies were collected in a $1.5 \mathrm{ml}$ sterile Eppendorf tube. Round bodies thus collected were washed first with $10 \%$ SDS (sodium dodecyl sulphate) and then with sterile glass distilled water and used for experimental studies, whenever needed. All four samples were processed and purified in the same manner.

For the scanning electron microscopy (SEM), the tissue, as well as the separated purified round bodies, were fixed in $2.5 \%$ glutaraldehyde and washed in 0.1 $\mathrm{M}$ phosphate buffer, followed by three changes of 15 minutes each at $4^{\circ} \mathrm{C}$. Post fixation was done in $1 \%$ 
$\mathrm{OsO}_{4}$ for 2 hours at $4^{\circ} \mathrm{C}$ and then washed in $0.1 \mathrm{M}$ Phosphate Buffer with 3 changes of 15 minutes each at $4^{\circ} \mathrm{C}$. The tissue was dehydrated in ascending concentrations of acetone for $15 \mathrm{~min}$ each. Critical point drying was done with liquid $\mathrm{CO}_{2}$ at $31.5^{\circ} \mathrm{C}$ (critical point) at 1100 Psi. Samples were mounted on the aluminium stubs and sputter coated with $35 \mathrm{~nm}$ thick film of gold.

For the transmission electron microscopy (TEM), the tissue was fixed in 2.5\% Karnovsky's fixative for 2 hours at $4^{\circ} \mathrm{C}$ and washed with $0.1 \mathrm{M}$ phosphate buffer, followed by three changes of $15 \mathrm{~min}$ each at $4^{\circ} \mathrm{C}$. Post fixation was done with $1 \%$ osmium tetroxide for 2 hours at $4^{\circ} \mathrm{C}$, followed by washing with $0.1 \mathrm{M}$ phosphate buffer with three changes of 15 min each at $4^{\circ} \mathrm{C}$. Water was removed from the sample by dehydrating it in ascending grades $(30 \%, 50 \%, 70 \%, 80 \%$, $90 \%, 95 \%)$ of dry acetone. Samples were dipped in each concentration of acetone for $30 \mathrm{~min}$ at $4^{\circ} \mathrm{C}$. The tissue was cleared by dipping it in toluene for $30 \mathrm{~min}$. Infiltration was done by using 1 part embedding medium and 3 parts of toluene - 1 hour, 2 parts embedding medium and 2 parts of toluene - 1 hour and 3 parts embedding medium and 1 part of toluene - 1 hour, and pure embedding medium -1 hour at $50^{\circ} \mathrm{C}$ followed by embedding in pure embedding medium (Araldite CY 212 10ml, dodecenyl succinic anhydride (DDSA) 10ml, 2,2-dimethoxy propane (DMP)-30 $0.4 \mathrm{ml}$, dibutyl phthalate $1.0 \mathrm{ml}$ ) using beam capsules and flat moulds. Embedded blocks were polymerized by keeping them at $50^{\circ} \mathrm{C}$ for 12-14 hours and then at $60^{\circ} \mathrm{C}$ for $24-28$ hours. About 100 isolated pure round bodies were fixed with $2 \%$ glutaraldehyde for 1 hour and centrifuged at 2000rpm for 5 minutes to form pellet. Round bodies were then washed three times with $0.1 \mathrm{M}$ phosphate buffer ( $\mathrm{pH}$ 7.2). Post fixation was done in $1 \% \mathrm{OsO}_{4}$ at $4^{\circ} \mathrm{C}$ for 1 hour at room temperature, followed by washing three times with PBS buffer. Pellet was embedded in $2 \%$ agar $\left(1 \mathrm{~mm}^{3}\right.$ blocks) and dehydrated in different ascending grades of acetone. Infiltration was done with acetone and resin mix (1:1) till the agar blocks settled at the bottom of the vial. The sample was embedded in fresh resin mix in beam capsules and polymerized by keeping them at $45^{\circ} \mathrm{C}$ for $12-18$ hours and then at $60^{\circ} \mathrm{C}$ for 12-18 hours.

The reagents and chemicals used were of highest quality, procured from standard internationally branded chemical companies. Formaldehyde, Cycloserine, Glutaraldehyde, ingredients of PBS were from Sigma Chemical Company. Durcupan araldite ACM mixture (epoxy resin, dibutyl phthalate, 964 hardener and accelerator), DMP-30, DDSA, Osmium tetroxide, uranyl acetate and lead citrate were purchased from Electron Microscopy Sciences, USA. Our sterile procedure used for extraction and purification of the round bodies and for subsequent processing for EM study rules out any chance of contamination leading to artefacts.

\section{RESULTS}

The whole mount of polyp containing round bodies, isolated round bodies and organism in round bodies, were studied with scanning electron microscopy. For removing araldite from sections, alcohol and $\mathrm{KOH}$ were used. Pieces of glass slides containing the sample to be studied were mounted on stubs using conducting silver paste, coated with a thin layer of gold and examined under LEO 1450-SEM. Scanning electron microscopy of whole mounts of polyps showed round bodies on the surface (Figure 1A). Figure 1B shows a stretched polyp surface with a round body buried beneath it. The isolated round body of Rhinosporidium seeberi shown in Figures 1C and 1D is 300-500 $\mu$ in diameter. The diameter of round bodies ranges between $50-500 \mu$ and that of the organism between $2-8 \mu$.

Figure 2A shows a shrunk round body that has partially released its contents. Figure 2B shows a round body that has ruptured, giving a typical pitcher-like appearance. Figure 2C shows a ruptured round body in 3 dimensions with a cave-like appearance, which has released its contents. The interior and exterior parts of the wall are clearly visible. The released singlecelled organism is seen adhering to the inner wall of the round body. Figure 2D shows a ruptured round body in three dimensions that has folded after releasing its contents. The released single-celled organism is seen adhering to the interior of the wall of the round body.

Figure 3A shows a symmetrically ruptured round body that has ruptured exactly from the middle, giving a typically opened-lid-like appearance. The exterior of the round body and slight interior are also visible, spilling its content in the surroundings.

Figures 3B and 3C show clusters of round bodies adhered to one another, showing their exterior. Figure $3 \mathrm{D}$ reveals a cluster of three round bodies with the middle one completely ruptured and one intact round body at the right terminal end. The exterior surface of the terminal ones is visible. Figures $4 \mathrm{~A}$ and $4 \mathrm{~B}$ show a single isolated round body in three dimensions that has freshly released its content. The outer and inner surfaces of the wall and the spilled-over organism are clearly visible. Figure 4B presents a round body with an inverted football-like appearance. A round body releasing single-celled organisms is shown in Figure $4 \mathrm{~A}, \mathrm{~B}$. The cell contents released from the rupture of a single mature round body is shown in Figure 4C,D. Two distinct cell types are visible, one approximately 2-3 times bigger than the other, thus showing the het- 

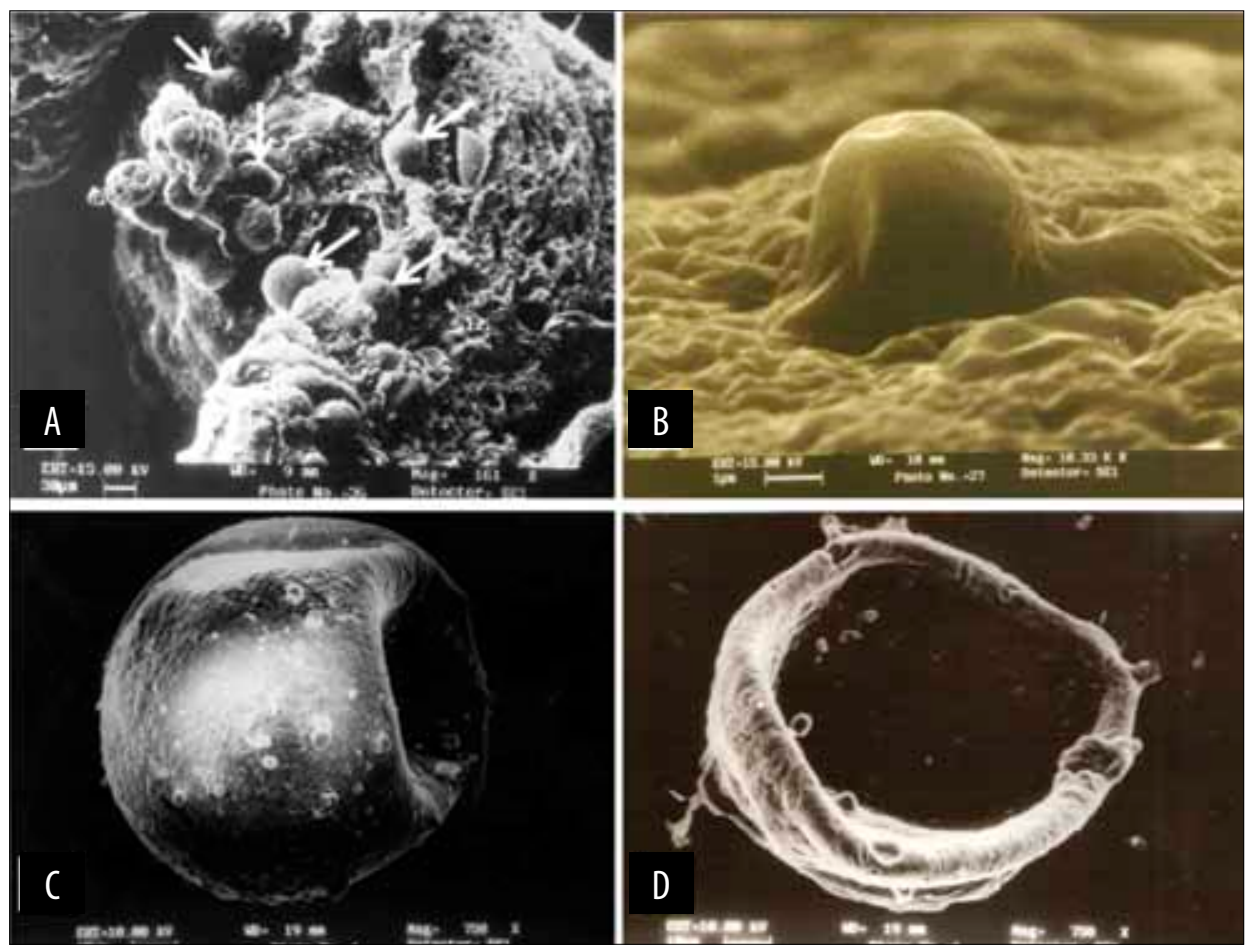

Figure 1 Typical round bodies of rhinosporidiosis under scanning electron microscope: A. Round bodies of rhinosporidiosis adhering to the polypoid mass. B. A stretched polyp surface with a round body buried beneath it. C. A single isolated round body with some spilled over single-celled organisms. D. A single round body showing invaginated appearance with some single-celled organisms stuck to its interior surface.
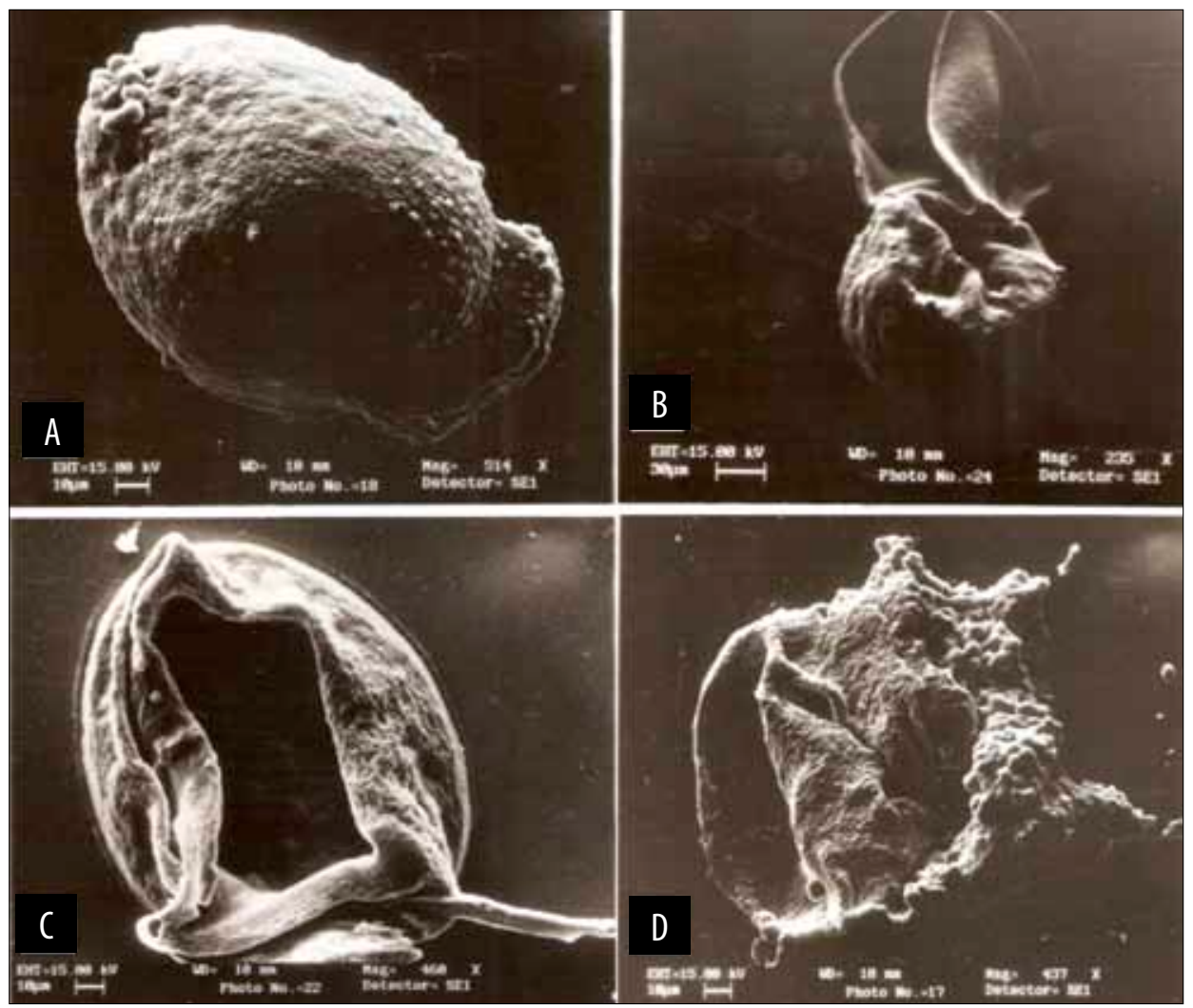

Figure 2 SEM showing round bodies that have ruptured to release their contents (spores): A. A shrunk round body that has partially released its contents giving a strawberry look. B. A round body that has ruptured giving a typical pitcher-like appearance. C. A ruptured round body in three dimensions with a cave-like appearance. D. A ruptured round body in three dimensions that has folded irregularly after releasing its content. 

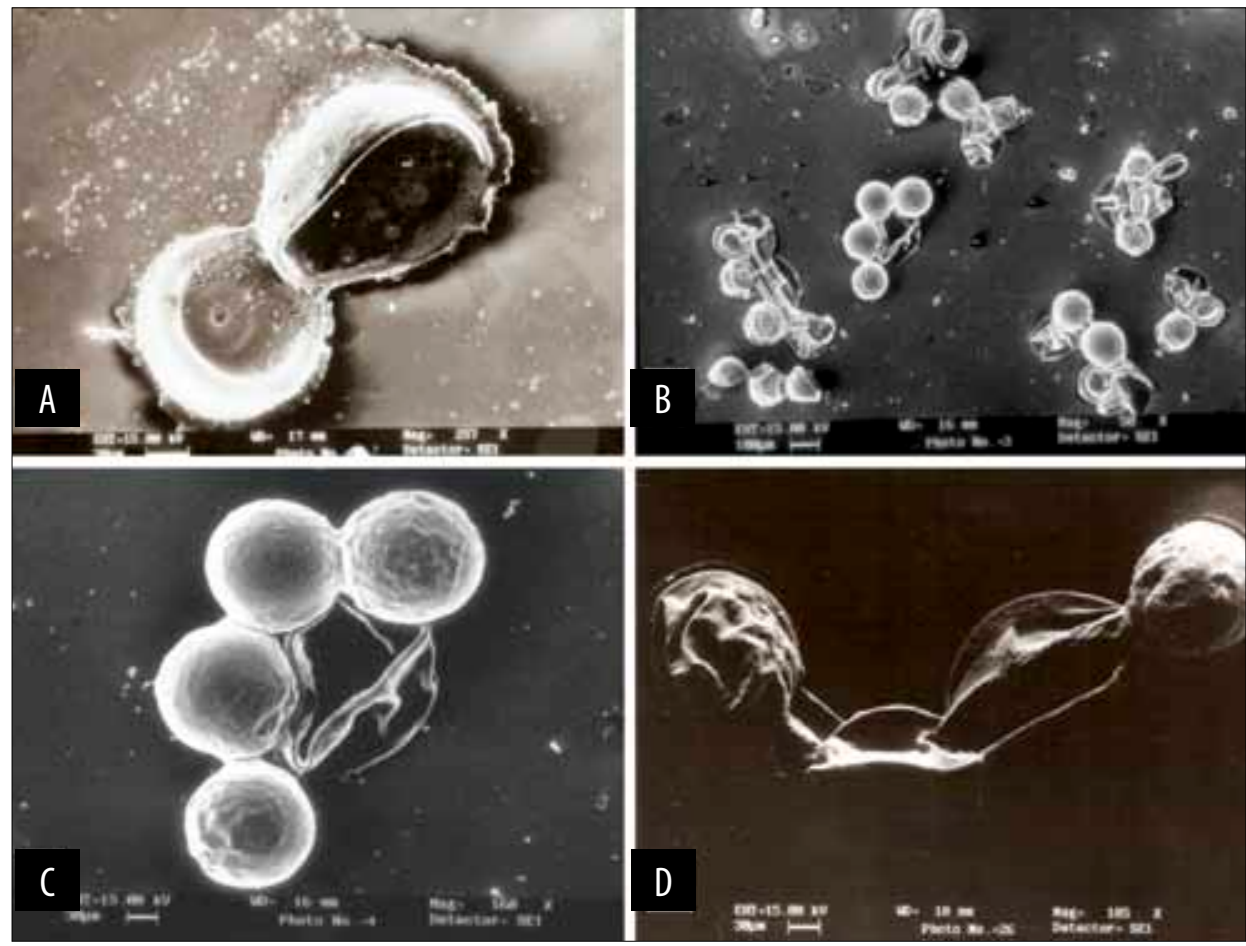

Figure 3. Round Bodies that have ruptured to release their contents (spores) under SEM: A. A round body that has ruptured from the midline and released its contents in a trail-like fashion. B. Clusters of round bodies with 2-5 round bodies in a bunch with individual round bodies connected to each other through polysaccharide coat. C. A cluster of five intact mature round bodies in high magnification showing their exterior surface and a ruptured round body. D. A bunch of three round bodies with one terminally intact, one ruptured and one round body that has partially shed its spores.

erogeneity of the single-celled organism. The released contents are heterogeneous, with some large round and some small wrinkle cells. Such distinct cellular phenotypes are present throughout the released contents. Organisms are seen to adhere to each other through bridges of coat polysaccharide. A magnified view of the released single-celled organism is shown in Figures $4 \mathrm{E}$ and $4 \mathrm{~F}$.

Figures 5A, 5B and 5C show round bodies cut open in transverse section. A magnificent view of the singlecelled organisms adhered to the wall of the round body is visible. The distinct polysaccharide coat of the round body and some single-celled organisms cut in transverse section are also visible. The single-celled organism shows the presence of some minute rounded spots. Distinct moulds are formed on the polysaccharide wall coat as a result of the release of a single-celled organism (Figure 5C). Figures 6A, 6B and 6C show a transmission electron micrograph of a round body revealing the coat of the round body and the cytoplasmic contents. The thick fibrillar polysaccharide coat of the round body is clearly visible. Three distinct wall phenotypes are present, including a trilamellar and electron-dense concentric rings surrounding a multilamellar wall of varying electron-lucent and electrondense structures. Tannic acid-uranyl acetate binding with mannose-rich polysaccharide in the wall of the round body can be seen (Figure 6D). The coat consists of glucomannan fibrils that are being continuously incorporated into the wall of the enlarging round body (Figure 6E).

Figures 7A to 7D show the exterior surface of a round body. Wavy ridges and grooves with noticeable elevations can be clearly seen on the exterior surface. Figure 7C reveals the exterior surface of a round body wherein some spilled-over single-celled organisms have stuck on its surface, possibly released from other wound bodies in vicinity. Figure 7D shows a magnified view of ridges, grooves and elevations of the exterior of the round body. Figures 7E, 7F, 7G, 7H present the interior of the round body. The interior surfaces have distinct dotted appearance (Figure 7E) that, under higher magnification, seem to be crystalline (Figure 7F-I).

\section{DISCUSSIONS}

Located in the upper respiratory tract, the nose performs many diverse functions. Besides being the primary olfactory organ, it also functions to filter, warm and humidify the inhaled air so that no damage is caused to the delicate distal tracheobronchial airways and the alveolar parenchyma of the lung. The nasal passage is referred to as the "scrubbing tower" for the 


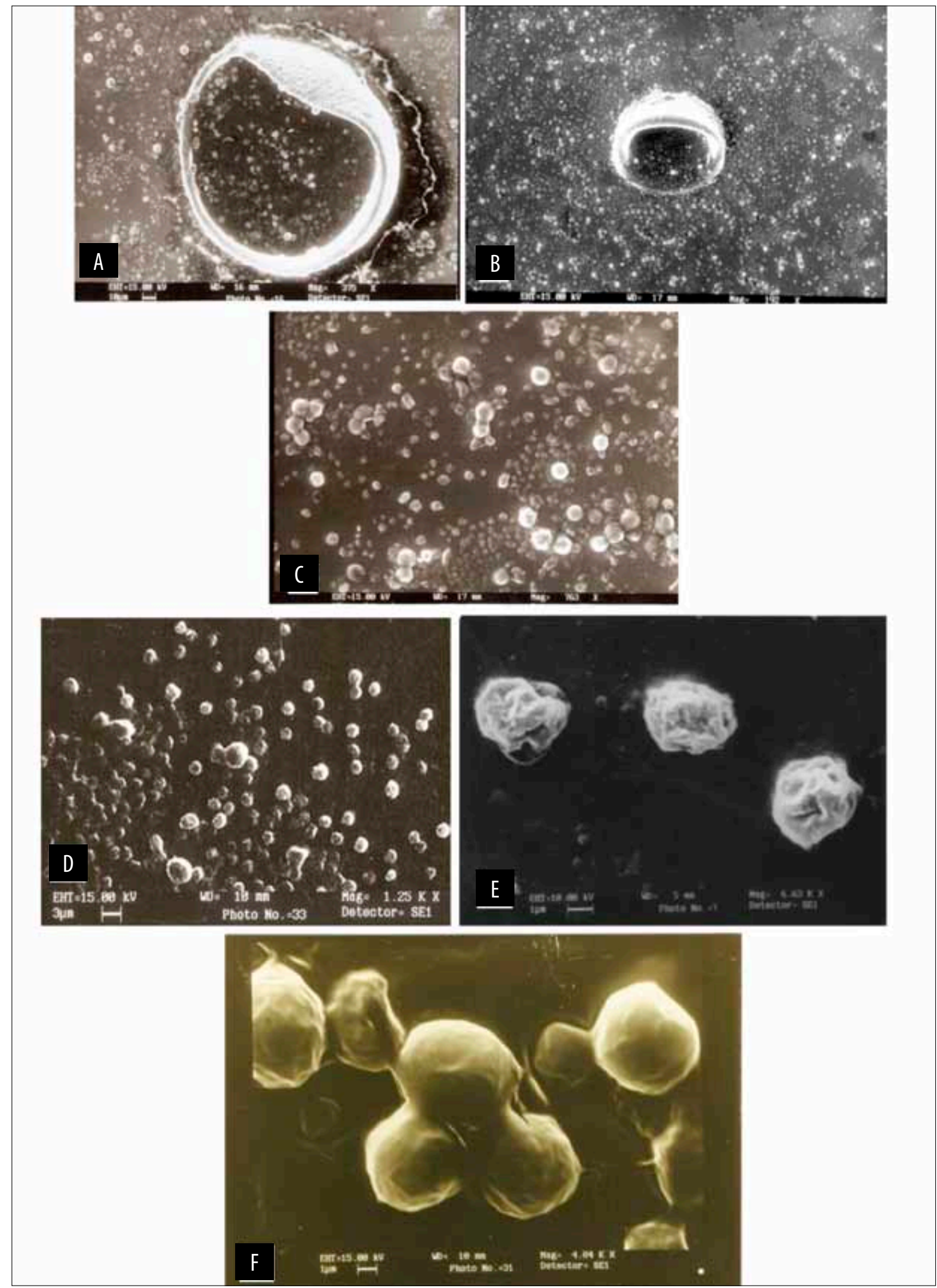

Figure 4 Heterogeneity of released spore contents under SEM: A. A single round body in three dimensions that has released its spore contents. B. A single invaginated round body releasing its cell contents. Organisms sticking to the inner and outer surface can be seen. C. Heterogeneity of cellular contents resulted from the rupture of a single round body. D. Mainly two kinds of cells - round and wrinkled - can be seen in the released cell contents. E. Released wrinkled cells under high magnification. F. Released round cells under high magnification. 


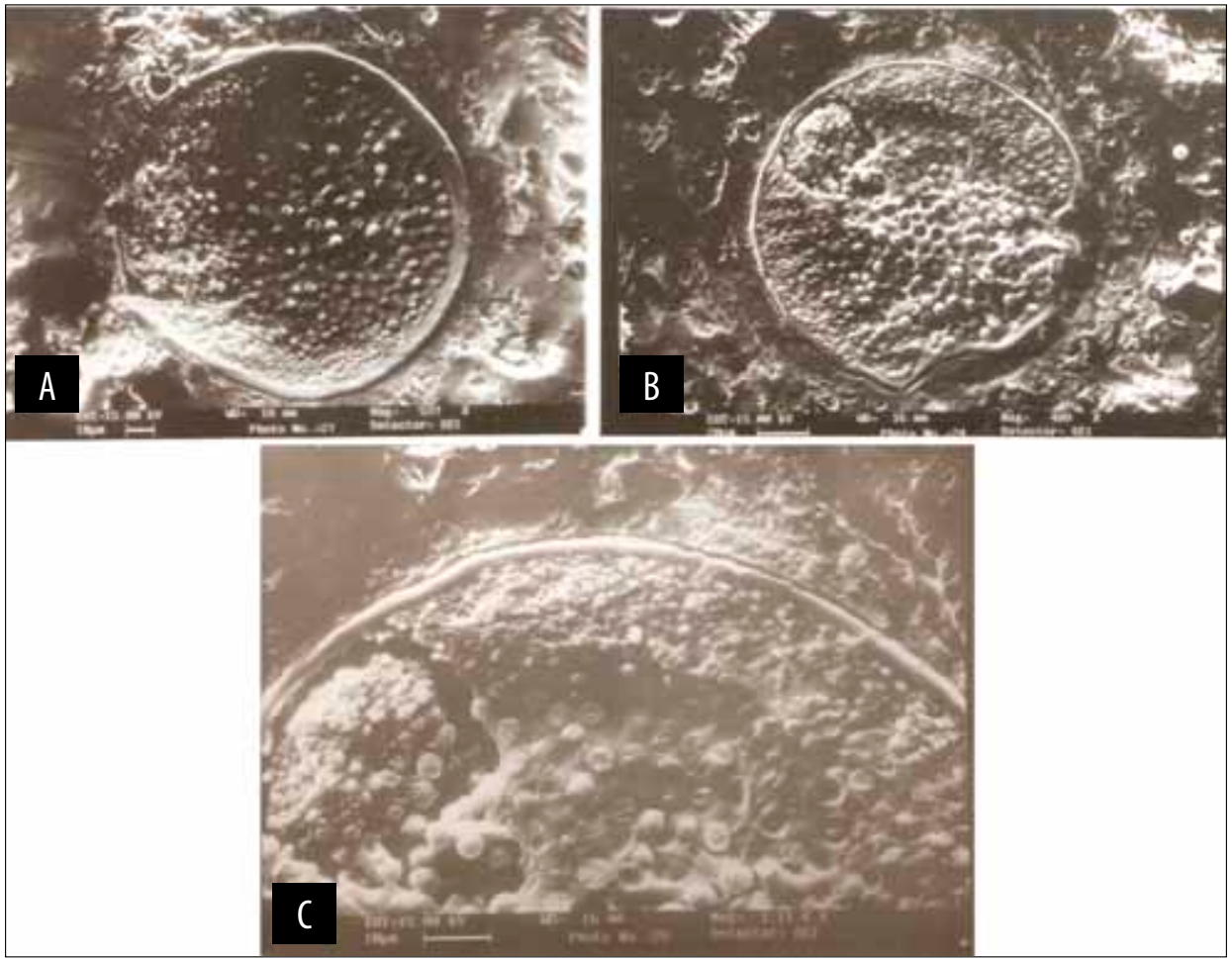

Figure 5 Round bodies cut open under SEM: A. A round body cut open showing spores (single-celled organism) attached to the round body, giving a slight convex appearance. B. Shed our spores leaving a mark on the interior surface of the round body, giving a slightly concave appearance. C. A cut open round body showing cut open spores adhering to the interior of the round body.

respiratory tract, as it absorbs water-soluble and reactive gases and vapours, traps inhaled particles, and metabolizes airborne xenobiotics. The nose may also be vulnerable to acute or chronic injury caused by exposure to high ambient concentrations of airborne toxic or infectious agents. Five morphologically and functionally distinct epithelia line the mammalian nasal passage - olfactory, respiratory, squamous, transitional, and lympho epithelial - and each nasal epithelium may be injured by an inhaled toxicant or a potential pathogen. Luminal surfaces of the nasal mucosa are covered by a watery, sticky material called mucus, produced by mucous (goblet) cells. The presence of a mass of oropharyngeal lymphoid tissues called the Waldeyer's ring (composed of the adenoid, and the bilateral tubule, palatine and lingual tonsils) has important function in the regional immune defence of the upper airways.

An environmental pathogen may be successful in invading the host cell by overcoming the host immune defence system, which includes skin resistance and mucosal secretions, nonspecific physical barriers and the specific immune responses involving lymphocytes. The pathogen possesses genes for virulence factors in its genome as survival strategy. To be able to establish infection, any pathogen looks for a transmission route, which is generally through the exposed skin or mucous membranes. To create pathogenicity, the patho- gen needs to maintain adherence to the host tissue and eventually invade the host and colonize. This is followed by a breach of the host defences and damage to the host by secretion of exotoxins or degradative enzymes. Pathogens may also exit the host to infect new hosts. In case of rhinosporidiosis, the nose and the nasopharynx are the commonest affected sites involved in more than $70 \%$ of cases. It is not known how the causative agent of rhinosporidiosis infects the nasal or other mucocutaneous tissues and what transmission route is followed for the invasion. Neither is there any clue of the infective stage. It is likely that the loss of communication of the nasal mucosal surface function, disturbance in mucin production, pathogens gaining control over the innate antimicrobial activity of nasal secretions and the effector lymphocytes function render the human host vulnerable to infection. Whether the single-celled organism or the mature or intermediate stage round body enters the human host are baffling questions.

The causative agent of rhinosporidiosis presents several enigmatic features. These unexplained phenotypic manifestations include laminated bodies, chromatin masses, vesicles and cell inclusions. Concentric laminated bodies had been interpreted variously as nuclear chromatin, nuclei in division and progenitors of spores ${ }^{4,8-10}$. A rare instance of peripheral concentric lamellae was met with in $R$. seeberi. Published data on 


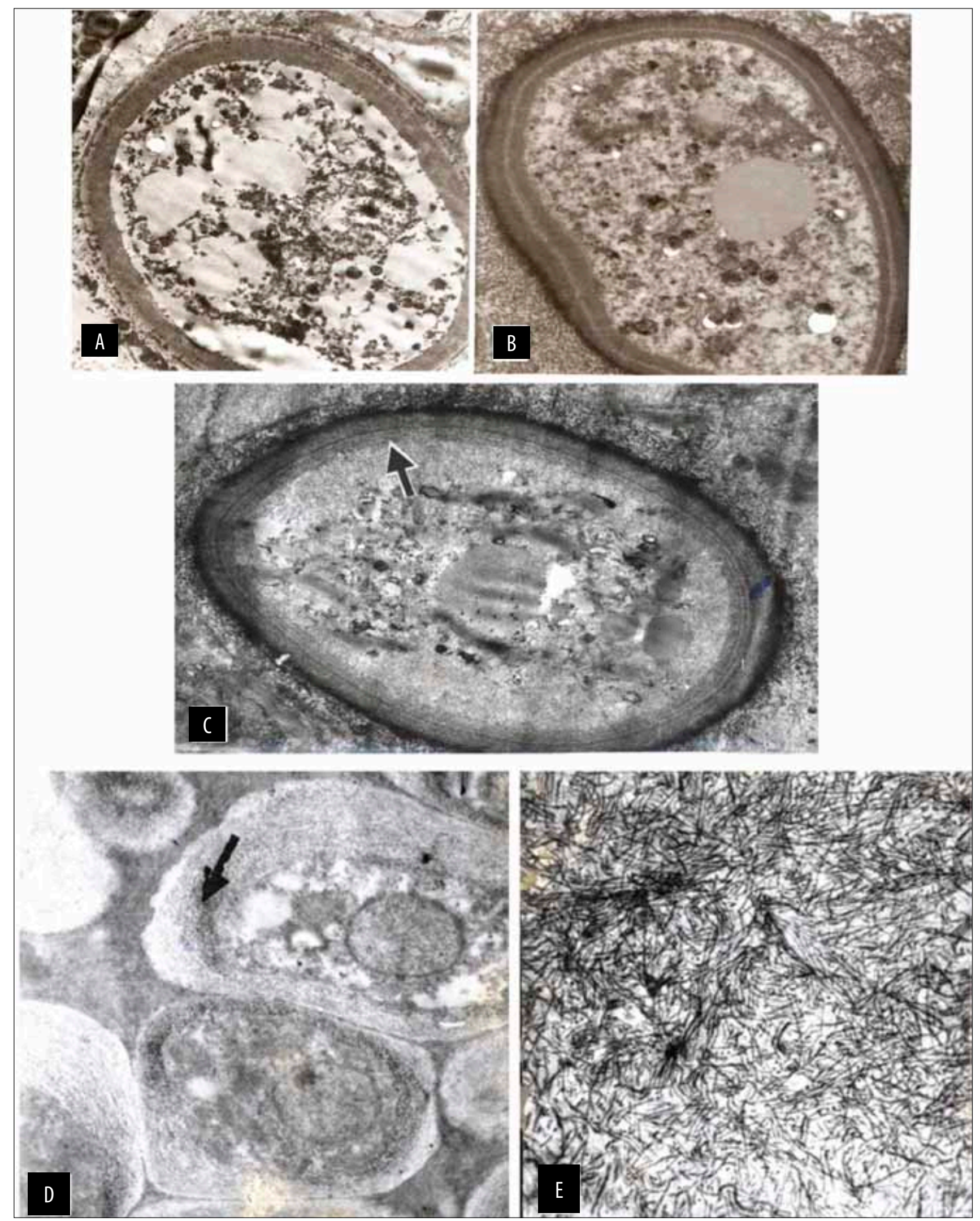

Figure 6 Round bodies cut open under the Transmission Electron Microscope: A. Round body showing the coat of the round body and the cytoplasmic contents. B. Round body coat showing a trilamellar pattern. C. Round body coat showing a unique concentric lamellar structure. D. Tannic acid-uranyl acetate binding with mannose-rich polysaccharide in the wall of the round body. E. Glucomannan fibrils in the coat of the round body. 


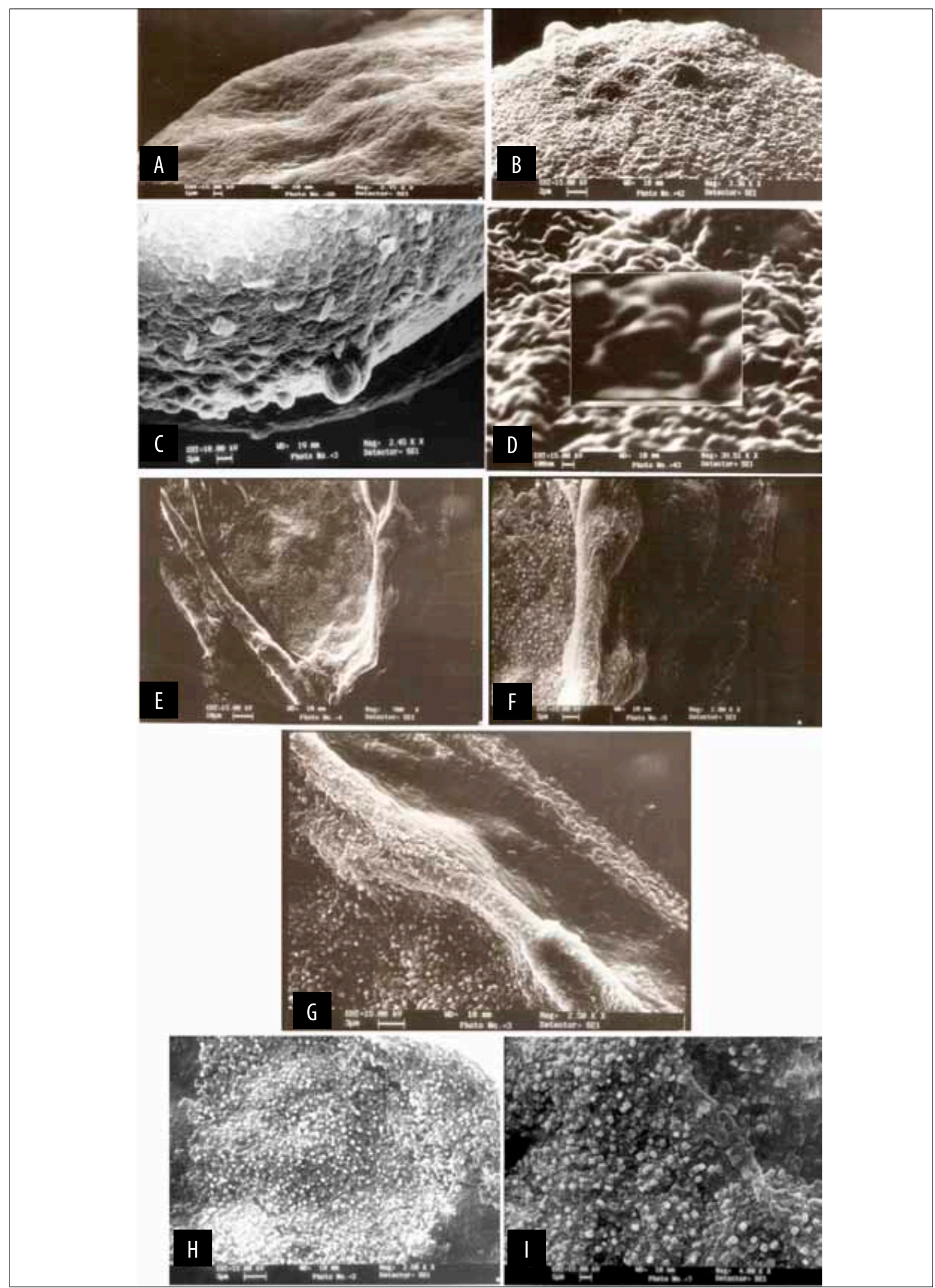

Figure 7 Exterior and interior aspect of the round body wall under SEM: A. Round body exterior showing wavy ridges and grooves. B. Round body showing pressure zones with spores buried under the exterior surface. C. Round body coat showing the exterior surface of a round body, wherein some spilled-over single-celled organisms (spores) have stuck to its surface. D. A magnified view of ridges, grooves and elevations of the exterior of the round body. E. Interior of the round body showing distinct dotted appearance. F. Interior of the round body showing folded appearance with granular interior. G. A folded round body interior with granular to crystalline transition. H. Interior of the round body showing distinct crystalline appearance. I. Interior of the round body under high magnification showing clear-cut crystalline structure. 
nuclei, nuclear division, dispersed nuclear chromatin and fragmentation of the nucleus into chromatin masses is inconsistent. Failure of earlier investigators to find round bodies in soil and aquatic habitats relates to the origin of these bodies in the host tissue. Ambient light and nutrient conditions in the host epithelium might induce the pathogen to differentiate into round bodies along with the growth of polyps in the nose. The process is probably linked to adaptive survival in an adverse microenvironment. This reprogramming must involve specific changes by which pathogen cells become geared for intracellular proliferation that produces innumerable daughter cells as well as synthesis of glucomannan for the wall enlarging the round body. This irreversible commitment has profound, lifelong implications for the affected human host. The daughter cells in a round body belonging to a genotypically identical clone possibly inherit a mechanism for the specific response to environmental stimuli. These cells, when liberated in the epithelium, repeat the cycle of morphogenetic transformation that leads to infinite number of round bodies and large polypoidal masses in the nose. Round bodies, comparable or exceeding in size the largest bacterium Thiomargarita namibiensis $(300 \mu)$, have been purified and isolated by us from the polyp tissue.

Seeber (1900) referred the coat of the round body as an envelope and described it to be thick, homogeneous, refringent and resistant to the action of acids and potash ${ }^{1}$. Vaughan (1903) stated that the wall was concentrically marked ${ }^{11}$. Our observations on the coat of the round bodies are consistent with EM observations of previous workers ${ }^{4,5,12}$. Beattie (1906) stated that the envelope was somewhat chitinous, with an external thin layer composed of fibrous tissue and an internal, much thicker hyaline layer ${ }^{13}$. He believed that the wall was a result of condensation of the crystal residuum rather than a secretion. This observation of Beattie is well substantiated in our studies, where the crystalline structure of the inner wall of the round body is distinctly prominent ${ }^{13}$. Furthermore, the inner crystalline coat of the round body in our sample extends peripherally, resembling the irregular layer with fibrillar extensions as reported by Moses et al. (1991) ${ }^{5}$. Teh et al. (1975) described the surface structures of the endospores of Rhinosporidium seeberi ${ }^{14}$. The surface of the endospores was found to be highly undulated with well-defined folds alternating with winding depressions. Each fold and depression averaged $50 \mu$ and $30 \mu$ respectively and were uniformly packed to give a distinctive cerebriform appearance characteristic of the sporangial verrucose coat of $R$. seeberi as described by Changus et al. (1970) ${ }^{15}$. The liberated single-celled spores shed as a result of bursting of mature round bodies in our sample were in conformity with Teh's observations, showing stiffly textured surface appear- ances ranging from wrinkly to round. A highly ordered developmental program correlating with spore morphological changes seems to operate in developing round bodies, revealing spatial and temporal molecular events fundamental for the reconstruction of cells of varied maturity. Besides the protective layers of spores, the round body coat confers unique mechanical properties as well, acting as a shield between the infective structure and host-induced environmental assaults. Further, Electron Microscopic studies of the structure of the spore coat are warranted to understand the dormancy exit, growth induction, wall composition and initiation of the infectivity cycle in rhinosporidiosis.

The results presented in this study exhibit some of the intriguing anatomical details of round bodies in various stages, adherent on tissue mass, in purified state, in transverse section and in mature state, when they release their single-cell organisms/spores. Exploration of the exterior of the coat of the round bodies showed stiff wavy ridges with noticeable elevations. Interestingly, the interior of the round body shows a highly crystalline structure. The inner surface is made of wonderfully distinct cubic crystals spread across the entire surface. The functional significance of the crystalline interior of the round body is not known at present but it may be of anchorage and trophic value. The stiff and hard exterior and highly crystalline interior may probably account for the organism's survival under severe environmental conditions and may be analogous to the paracrystalline cell wall surface layers (S-layers) present on a wide range of gram-positive, gram-negative eubacteria and archaebacteria ${ }^{16,17}$. These S-layers are considered to play an important role in the interaction between the cells and the environment, and provide protection from the hostile host's immune responses. Likewise, the complex structural manifestations of the organisms released from a mature round body may be considered analogous to the resistant bacterial spores, which can withstand extremes of hostility. Two types of organismal cell populations in the round body differing in size and shape present phenotypic plasticity. These electron microscopic images hint towards sophisticated and organized survival and proliferation tactics being exercised by $R$. seeberi.

We and others have noted round bodies in polyps in various stages of maturity. The trigger for maturation is a crucial signal which will eventually decide the shedding of single celled organism through a rupture in the wall; development of a single-celled organism into a new round body and growth of the polyp due to proliferation and initiation of a new cycle of infection. It is not unlikely that round bodies possess a genetic algorithm for maturation that leads to changes and modifications in the cell wall of a mature round body 
and synthesis of cell wall material, while an infective stage grows into a mature round body. Probably, a precise and sophisticated reprogramming mechanism triggered by a specific signal accomplishes multiple cycles of infection leading to a nonstop divisive and proliferative process, resulting into an increase in the size of the polyp. The case histories of patients present a considerable time window from the day of infection to the development of symptoms and awareness about the presence of a sizable polyp. Therefore, it is reasonable to believe that the infective stage could stay dormant for quite some time until it gets a favourable environment for proliferation and growth. Bizarre manifestations and size variation of growing round bodies in various stages of maturation provide the stimulus to investigate molecular events taking place in the developing round bodies. If round bodies only in a particular stage of maturity and development initiate infection needs to be investigated. Whether a particular growth stage of a round body or enclosed single-celled spores act as dormant propagules remains a topic of intellectual curiosity. Re-availability of nutrients might act as a key signal for exit from dormancy, but in case of nasal rhinosporidiosis, nasal epithelium could serve as a sustained source of nutrients, unless the host itself is malnourished. Moreover, since the socioeconomic status has no consistent relation with the etiology of rhinosporidiosis, definitive stimuli for exit from dormancy may be a factor other than nutrients, such as the immune status of the individual, changed weather or climatic conditions or exposure to certain environs.

The round body is unequivocally an adaptive transformed state of single-celled pathogen undergoing various kinds of adaptations. Several bacteria are known to use complex processes to cope with extremes by differentiating into specialized cells. Some meet the challenge of an adverse host environment by developing into a resistant cell stage or through encystment ${ }^{18,19}$. Round bodies in clinical samples notably lack some typical features such as colony formation; however, the presence of a macrocolony, a biofilm resembling a colony-like structure has been observed in culture studies ${ }^{20,21}$. The electron microscopic features of the wall of the round body shown here certainly provides evidence of the complex structural organization of the causative agent of rhinosporidiosis. The round body is a unique alternative heritable phenotype of pathogen and may have genetic determinants for the transformation process. The details of such a transformation are not clear at present, but genes involved in the rapid response mechanism controlling the circadian clock may be attributed to regulate the process. Levy et al. (1986) demonstrated the interaction of the causative agent of rhinosporidiosis with epithelial cells in vitro ${ }^{22}$. Authors not only found organ- isms adhering to the HRT monolayers, but also observed formation of polyp-like structures, mature sporangia developing and releasing spores into the medium. The complete development of $R$. seeberi in vitro appeared to require interaction with mammalian cells. Comprehensive electron microscopy of these formations may reveal finer comparative details of the coat structure of the round bodies in vivo and in vitro. The composition and the structure of the round body wall might act as a key regulatory factor in the maturation and dispersal of single-celled spores, leading to development of new round bodies in a chain reaction manner. The various developing stages of the pathogen in rhinosporidiosis seem to exploit the host microenvironment by infecting the host tissue differently through specific evasions. More elaborate investigations are required to further advances on evolutionary and host-pathogen interaction aspects of the causative agent of rhinosporidiosis.

Dapsone is the only drug of choice following surgical excision in rhinosporidiosis. It has immunomodulatory, anti-inflammatory and growth arresting effects. Job et al. (1993), Venkateswaran et al. (1997), through electron microscopic studies, confirmed arrest of the maturation of the spores as evident from the reduction in the number of single and dividing spores ${ }^{7,23}$. Dapsone treatment resulted in collapse of hyalinised sporangial walls as well as marked degenerative changes in the sporangia with loss of cytoplasmic material. As an oral sulphonamide antibiotic, Dapsone targets a metabolic pathway in bacteria as a competitive inhibitor of the enzyme dihydropteroate synthase (DHPS). DHPS is of vital importance in the synthesis of folate, which in turn is required for nucleic acid biosynthesis. When nucleic acids are not formed, the cell cannot divide, hence the growth is inhibited. As an anti-inflammatory topical preparation, Dapsone inhibits the enzyme myeloperoxidase, lysosomal enzymes, multiple prostaglandins and leukotrienes and protects host cells against cellular injury.

\section{CONCLUSIONS}

Additional studies on the coat structure of the round bodies of rhinosporidiosis may help in understanding the evasion of the host mucosal barrier mechanisms by the causative pathogen. How RB coat morphology can facilitate adhesion and internalization for manipulation of the host cell cytoskeleton and signalling pathways to lead to a cancer-like proliferative growth remains an interesting aspect of investigation. Furthermore, corroboration of EM findings with morphological and genetic determinants may provide deeper insight into the role of $\mathrm{RB}$ and spore coat dynamics in the mechanism of disease progression in 
rhinosporidiosis. An enhanced understanding of the biology of the cell wall synthesis in round bodies must provide a clue for the development of targeted therapeutics in rhinosporidiosis.

Conflict of interest: The authors have no conflict of interest.

Contribution of authors: All authors have equally contributed to this work.

\section{REFERENCES}

1. Seeber G.R. - Un nuevo espongiaria parasito del hombre das cases encontrados en polipos nasales. Thesis Universidad Nacional de Buenos Aires, Boullosa, 1900.

2. Kwon-Chung K.J., Bennett J.E. - Infections due to miscellaneous molds. In: Kwon-Chung K.J., Bennett J.E., editors. - Medical Mycology. Lea \& Febiger, Philadelphia, PA, 1992;p.733-739.

3. Chatterjee P.K., Khatua C.R., Chatterjee S.N., Dastidar N. - Recurrent multiple rhinosporidiosis with osteolytic lesions in hand and foot: A case report. J Laryngol Otol., 1977;91 (8):729-734.

4. Kannan-Kutty M., Eng Chuan Teh. - Rinosporidium seeberi: an electron microscopic study of its life cycle. Pathology, 1974;6(1):63-70.

5. Moses J.S., Balachandran C., Singh B., Shanmugan A., Moses D. Rhinosporidium seeberi: light, phase contrast, fluorescent and scanning electron microscopic study. Mycopathologia, 1991;114(1):17-20. PubMed PMID: 1857398.

6. Azadeh B., Baghoumian N., El-Bakri O.T. - Rhinosporidiosis: immunohistochemical and electron microscopic studies. J Laryngol Otol., 1994;108(12):1048-1054.

7. Venkateswaran S., Date A., Job A., Mathan M. - Light and electron microscopic findings in rhinosporidiosis after dapsone therapy. Trop Med Int Health., 1997;2(12):1128-1132.

8. Savino D.F., Margo C.E. - Conjunctival Rhinosporidiosis: Light and electron microscopic study. Ophthalmology, 1983;90(12):1482-1489.
9. Kennedy F.A., Buggage R.R., Ajello L. - Rhinosporidiosis: a description of an unprecedented outbreak in captive swans (Cygnus spp.) and a proposal for revision of the ontogenic nomenclature of Rhinosporidium seeberi. J Med Vet Mycol., 1995;33(3):157-165.

10. Thianprasit M., Thagerngpol K. - Rhinosporidiosis. Curr Top Med Mycol., 1989;3:64-85.

11. Vughan J.C., O'Kinealy F. - Localised psorospermosis of the mucous membrane of the septum nasi. Proc Laryng Soc London, 1903;10:109-112.

12. Vanbreuseghem R. - Ultrastructure of rhinosporidium seeberi. Int J Dermatol., 1973;12(1):20-28.

13. Beattie J.M. - Rhinosporidium kinealyi: a sporozoan of the nasal mucous membrane. J Path Bact., 1906;11:270-275.

14. Teh E.C., Kannan-Kutty M. - Rhinosporidium seeberi: spherules and their significance. Pathology, 1975;7(2):133-137.

15. Changes G.W., Yonan T.N., Changus J.E. - Natural history of rhinosporidiosis. Septieme Congress International de Microscopic Electronique. Grenoble, 1970;p.875-876.

16. Sleytr U.B., Messner P., Pum D., Sára M. - Crystalline bacterial cell surface layers (s layers): from supramolecular cell structure to biomimetics and nanotechnology. Angew Chem Int Ed Engl., 1999;38(8):1034-1054. doi: 10.1002/ (SICI) 1521-3773(199990419)38:8<1034::AID-ANIE1034>3.0CO;2\#.

17. Hovmöller S., Sjögren A., Wang D.N. - The structure of crystalline bacterial surface layers. Prog Biophys Molec Biol., 1988;51(2):131-163.

18. Hengge-Aronis R. - Survival of hunger and stress: the role of rpoS in early stationary phase gene regulation in E. coli. Cell, 1993;72(2):165-168.

19. Wick M.J., Madara J.L., Fields B.N., Normark S. J. - Molecular cross talk between epithelial cells and pathogenic microorganisms. Cell, 1991;67(4):651-659.

20. Ahluwalia K.B. - Culture of the organism that causes rhinosporidiosis. J Laryngol Otol. 1999;113(6):523-528.

21. Dhaulakhandi D.B., Ravi A.K., Garg L.C., Ahluwalia K.B. - Symmetry patterning by the causative organism of rhinosporidiosis in culture. Romanian Journal of Rhinology, 2017;7(25):2017:19-26.

22. Levy M.G., Meuten D.J., Breitschwerdt E.B. - Cultivation of Rhinosporidium seeberi in vitro: interaction with epithelial cells. Science, 1986;234(4775):474-476

23. Job A., Venkateswaran S., Mathan M., Krishnaswami H., Raman R. Medical therapy of rhinosporidiosis with dapsone. J Laryngol Otol., $1993 ; 107(9): 809-812$. 